Journal of Patient-Centered

\title{
'No Pink Ribbons': How Women's Lived Experiences With Breast Atypia Inform Decisions Involving Risk-Reducing Medications
}

\author{
Sarah L. Goff \\ Reva Kleppel \\ Grace Makari-Judson
}

Follow this and additional works at: https://aah.org/jpcrr

Part of the Behavior and Behavior Mechanisms Commons, Community Health and Preventive Medicine Commons, Health Services Research Commons, Oncology Commons, Pharmacy and Pharmaceutical Sciences Commons, and the Tissues Commons

\section{Recommended Citation}

Goff SL, Kleppel R, Makari-Judson G. 'No pink ribbons': how women's lived experiences with breast atypia inform decisions involving risk-reducing medications. J Patient Cent Res Rev. 2018;5:158-66. doi:

10.17294/2330-0698.1594

Published quarterly by Midwest-based health system Advocate Aurora Health and indexed in PubMed Central, the Journal of Patient-Centered Research and Reviews (JPCRR) is an open access, peer-reviewed medical journal focused on disseminating scholarly works devoted to improving patient-centered care practices, health outcomes, and the patient experience. 


\title{
'No Pink Ribbons': How Women's Lived Experiences With Breast Atypia Inform Decisions Involving Risk-Reducing Medications
}

\author{
Sarah L. Goff, MD, ${ }^{1,2}$ Reva Kleppel, MSW, MPH, ${ }^{1}$ Grace Makari-Judson, MD ${ }^{3}$ \\ ${ }^{1}$ Division of General Medicine, University of Massachusetts Medical School-Baystate, Springfield, MA; ${ }^{2}$ Institute for \\ Healthcare Delivery and Population Science, University of Massachusetts Medical School-Baystate, Springfield, MA; \\ ${ }^{3}$ Division of Hematology-Oncology, University of Massachusetts Medical School-Baystate, Springfield, MA
}

Purpose Atypical hyperplasia (AH) is associated with a nearly 4-fold elevation of lifetime risk for breast cancer,
and lobular carcinoma in situ (LCIS) is associated with a 7- to 8-fold risk. Women with AH/LCIS make
numerous decisions in the course of treatment, including whether to take a risk-reducing medication,
an option relatively few women pursue. We explored women's decision-making processes through
patient narratives in an effort to inform decision supports for AH/LCIS.

Methods We conducted in-depth interviews with 20 English-speaking women with AH/LCIS and no subsequent diagnosis of invasive breast cancer who had enrolled in the Rays of Hope Center for Breast Cancer Research patient registry between April 5, 2012, and March 31, 2016. Interviews were audiotaped, professionally transcribed, and qualitatively analyzed using thematic qualitative content analysis.

Results We identified three major narrative themes: 1) experiences with medical care; 2) decision-making; and 3) making sense of $\mathrm{AH} / \mathrm{LCIS}$. Each major theme had several subthemes, many of which map onto existing decisional theories and heuristics. Subthemes included the impact of life context on diagnosis meaning, emotional responses, changes in self-concept and body image, and understanding of the risk-benefit of risk-reducing medications.

Conclusions This narrative analysis offers important insights into how lived experience may influence decisionmaking for women with AH/LCIS. Decision supports that focus not only on analytic decisional processes, but also patients' subjectivities and decisional heuristics, could prove useful for women and their health care providers. (J Patient Cent Res Rev. 2018;5:158-166.)

Keywords atypical hyperplasia; breast; breast cancer prevention; shared decision-making; patient narrative; qualitative

“There's really no place for someone like me. There's no Pink [ribbon] to celebrate it and there are no support groups ... but it's still scary and it's still a big decision."

- Woman with atypical hyperplasia of the breast

lthough atypical hyperplasia $(\mathrm{AH})$ of the breast
is rare in the general population $(2.4$ out of
10,000 screening mammograms), ${ }^{1}$ it accounts

Correspondence: Sarah L. Goff, MD,

University of Massachusetts Medical School-Baystate,

3601 Main Street, 3rd Floor, Springfield, MA 01107

(sarah.goffmd@baystatehealth.org) for $10 \%$ of the benign breast disease found on biopsy. ${ }^{1}$ Despite AH's benign designation, it is associated with a 30\% risk (relative risk: 4.0 ) of developing invasive breast cancer in the 25 years following diagnosis. ${ }^{2-6}$ Patients diagnosed with lobular carcinoma in situ (LCIS), a benign breast lesion managed similarly to $\mathrm{AH}$, carry a $30 \%-40 \%$ risk (relative risk: 8.0 ) of developing invasive breast cancer over a lifetime. ${ }^{7}$ This is in contrast to the increased risk for invasive breast cancer associated 
with alcohol use (relative risk: 1.32$)^{8}$ and obesity in postmenopausal women (relative risk: 1.26). ${ }^{9}$

Women with AH/LCIS and their health care providers face several decision-making conundrums. For example, there is equipoise regarding optimal approaches to breast cancer screening for women with AH/LCIS (eg, American Cancer Society guidelines "do not recommend for or against" the use of magnetic resonance imaging in this population). ${ }^{10}$ Decisions about use of risk-reducing medications present challenges. Hartmann et al, in a state-of-the-science review, ${ }^{11}$ noted that despite the effectiveness of risk-reducing medications, ${ }^{12-14}$ many women elect not to take them. An estimated $15.5 \%$ of women age 35-79 years are eligible to use medication for primary prevention of breast cancer, ${ }^{15}$ but less than $0.3 \%$ elect to do so. ${ }^{16}$

Theoretical explanations for this phenomenon include low perceived personal risk for breast cancer, concerns about medication side effects, psychological differences between preventing the possibility of developing breast cancer versus treating breast cancer, physician discomfort with prescribing risk-reducing medications, and women's incomplete understanding of both their risk for breast cancer and the risk-benefit associated with risk-reducing medications. Although choosing not to take a risk-reducing medication may be the result of fully informed shared decision-making, several of these explanatory theories speak to potential failures to communicate risk effectively to women.

Shared decision-making has been increasingly viewed as the most ethical approach to medical decisionmaking when there is equipoise in guidelines. When a shared decision-making approach is used, health care providers elicit patient preferences regarding participation in decision-making and provide understandable information about the options for diagnosis, treatment, and/or management. The health care provider also provides understandable information about the risks and benefits of pursuing or not pursuing a given option and elicits the patient's values, utilities, and life conditions that may factor into his or her decision. Decision aids can help facilitate use of shared decision-making principles. ${ }^{17}$

We asked women with AH/LCIS to share their experiences, thoughts, and feelings related to their diagnosis of AH/LCIS, with the aim of identifying and understanding factors that may contribute to how they made decisions related to their diagnosis, both in general and specific to the use of risk-reducing medications. This type of narrative approach offers the opportunity to explore a chronology of actions, feelings, and embeddedness as well as how an individual's story nests within her life. ${ }^{18}$ Our ultimate goal was to inform future development and testing of a novel decision aid for women with AH/LCIS and their health care providers.

\section{METHODS \\ Population and Recruitment}

We identified women who had enrolled in the Rays of Hope Center for Breast Cancer Research patient registry between April 5, 2012, and March 31, 2016; were English speaking; were 30-80 years of age at the time of diagnosis of atypical ductal hyperplasia, atypical lobular hyperplasia, or LCIS; had consented to be contacted through the registry for research purposes; and who had not experienced a subsequent diagnosis of breast cancer. All women who are at least 18 years of age, have had an excisional breast biopsy or breast surgery (reduction mammoplasty, lumpectomy, or mastectomy), and have been seen by a health care provider at Baystate Medical Center (Springfield, MA) are invited to participate in the registry. Registry participants reflect the demographics of women who have had excisional breast biopsies at Baystate. Written informed consent is obtained for all registry participants by registry research staff, and Baystate's institutional review board approved the study protocol.

Women with a diagnosis of ductal carcinoma in situ or who had been diagnosed with breast cancer subsequent to their AH/LCIS diagnosis were excluded because we were most interested in the perspectives of women facing decisions related to primary breast cancer prevention alone.

We mailed three rounds of invitation letters (May 2015, September 2015, May 2016) to potentially eligible women. The letter described the study and asked potential participants to call the study's research assistant if they were interested in learning more about the study or if they knew that they did not want to participate. The letter also stated that if the research 
team did not hear back, a team member would call the recipient to address any questions she might have and to further assess her interest in participating.

We sent invitation letters to all women who met eligibility criteria during the study time frame $(n=43)$. Four women called the study research assistant to express interest in participating, and an additional 16 women were recruited during follow-up phone calls. We stopped recruitment when theoretical saturation was reached (no new concepts in four sequential interviews). ${ }^{19}$

\section{Interviews}

The research team developed an interview guide (Appendix 1, p. 166) and pilot tested it with female hospital staff and medical residents to assess the guide for clarity and content. Authors S.L.G. and R.K. developed an a priori code book based on existing literature regarding decision theory. A second-year female internal medicine resident conducted the first 5 interviews. The primary investigator, who has extensive experience using qualitative methods, ${ }^{20-23}$ trained the resident in qualitative interview techniques. A research staff member, who is trained as a public health social worker and has expertise in conducting in-depth interviews, conducted the subsequent 15 interviews. One participant's husband accompanied her to the interview; the rest of the interviews were conducted with the participant alone.

Participants completed a brief demographic survey at the end of their interview and were offered a $\$ 25$ gift card in appreciation of their time. All interviews were audiotaped and transcribed by a professional transcriptionist.

\section{Analysis}

A deductive approach (ie, begin with a priori codes based on prior research and theory) was used to identify broad themes in the first 4 transcripts, then the a priori code book was revised to reflect the new themes identified. The research team (S.L.G., R.K.) then identified granular concepts through independent iterative open line-coding of the transcripts, labeling new concepts as they were identified. Line-code disagreements were resolved through discussion for the first 15 transcripts, maintaining an "audit trail" of coding decisions. R.K. then coded the final 5 transcripts and reviewed coding decisions with S.L.G. New broad themes were identified as coding progressed, using memos attached to lines of coded text to track these emerging themes.

Codes continued to be organized into major themes and subthemes during secondary (axial) coding, with researchers returning to the transcripts as needed. ${ }^{24}$ Finally, identified themes were triangulated with heuristic decisional theory, both to ground the analysis in existing theory and to explore the potential for a theory-based rationale for development of a novel decision aid for women diagnosed with AH/LCIS and their health care providers. This analytic approach relied on qualitative interpretation of the data, with rigor derived from use of two independent coders and grounding the analysis in the transcript data and theory.

\section{RESULTS}

Of 20 study participants, $14(70 \%)$ were between 45 and 64 years of age, $14(70 \%)$ identified as white, nearly half $(n=9)$ had a bachelor's degree or higher, and the majority $(n=16)$ were employed for wages (Table 1). The median time from diagnosis to interview for the 15 women with diagnosis dates was 1 year (range 0.5 to 4.0 years). Two women had elected to have prophylactic mastectomies. Interviews lasted from 15 to 45 minutes.

We identified three major themes, each with multiple associated subthemes. Major themes included 1) experiences with medical care, 2) decision-making, and 3) making sense of AH/LCIS. These themes and their associated subthemes are described in detail hereafter, along with illustrative quotes; many additional quotes are reported in Table S1 (online only).

\section{Experiences With Medical Care}

Women described a range of experiences with health care providers and the health care system in relation to their AH/LCIS. Three dominant subthemes emerged: a) overall experiences; b) mixed messages; and c) advice to other women.

Overall Experiences With Care: Many women in the study had positive experiences with their health care providers and the health care system during the process 
Table 1. Participant Characteristics

\begin{tabular}{|c|c|}
\hline Characteristic & n (\%) \\
\hline \multicolumn{2}{|l|}{ Age, mean (SD) } \\
\hline 35-44 years & $4(20 \%)$ \\
\hline $45-54$ years & $10(50 \%)$ \\
\hline $55-64$ years & $4(20 \%)$ \\
\hline$>64$ years & $2(10 \%)$ \\
\hline \multicolumn{2}{|l|}{ Race } \\
\hline Hispanic & $1(5 \%)$ \\
\hline Native American & $1(5 \%)$ \\
\hline Black & $4(20 \%)$ \\
\hline White & $14(60 \%)$ \\
\hline \multicolumn{2}{|l|}{ Annual income } \\
\hline$<\$ 25,000$ & $1(5 \%)$ \\
\hline$\$ 25,000-\$ 49,999$ & $5(25 \%)$ \\
\hline$\$ 50,000-\$ 100,000$ & $5(25 \%)$ \\
\hline$>\$ 100,000$ & $3(15 \%)$ \\
\hline Prefer not to say & $4(20 \%)$ \\
\hline Not provided & $2(10 \%)$ \\
\hline \multicolumn{2}{|l|}{ Marital status } \\
\hline Single & $1(5 \%)$ \\
\hline Separated & $1(5 \%)$ \\
\hline Divorced & $2(10 \%)$ \\
\hline Married & $16(80 \%)$ \\
\hline \multicolumn{2}{|l|}{ Work status } \\
\hline Retired & $2(10 \%)$ \\
\hline Employed for wages & $16(80 \%)$ \\
\hline Not provided & $2(10 \%)$ \\
\hline \multicolumn{2}{|l|}{ Education } \\
\hline High school/GED & $3(15 \%)$ \\
\hline Some college & $3(15 \%)$ \\
\hline Associate's degree & $3(15 \%)$ \\
\hline Bachelor's degree & $6(30 \%)$ \\
\hline Some graduate & $1(5 \%)$ \\
\hline Graduate degree & $2(10 \%)$ \\
\hline Not provided & $2(10 \%)$ \\
\hline
\end{tabular}

of being diagnosed and treated. Good communication and trust typified the positive descriptions of care.

"I have to say the oncologist was wonderful. She was ... calming ... very helpful and informative ... especially when I was first diagnosed. She did diagrams and all that sort of thing."
Women also described negative experiences, including unanticipated complications, feeling that their concerns were minimized, and feeling that they had questions that remained unanswered.

"I said I would rather have an [definitive] answer [about the abnormality noted on the mammogram] sooner, and he [physician] says — 'Well, everything that I see says you're fine. You don't even need this [breast biopsy]. I don't know why you're doing it.' He was very dismissive, and he says - 'I guess if you really want to we can go ahead and do it.",

Mixed Messages: Some women felt that they received conflicting guidance from health care providers within and across both specialties and institutions. For example, different doctors expressed differing opinions about diagnostic and management approaches.

"How can someone tell me to take both boobs off, and how can someone [else] tell me - let's just watch it?"

Women recalled recommendations for mammography and clinical breast examination ranged from every 6 months to yearly.

Advice to Other Women: Women made the following recommendations for others facing a similar diagnosis: ask a lot of questions, get a second opinion if you have any doubt, be proactive, and do your own research. Women also offered advice to physicians: offer written information about both the disease and management options, and provide explanations over time so they can be heard, understood, and absorbed.

\section{Decision-Making}

Four subthemes related to decision-making were identified: a) preferred role in decision-making; b) decisional inputs; c) risk-reducing medication; and d) understanding risk and benefit.

Preferred Role in Decision-Making: Women varied in the extent to which they wished to actively participate in decisions regarding biopsy, risk-reducing medication, postbiopsy breast cancer screening and, for some women, mastectomy. Some preferred to follow their health care providers' recommendations without much discussion.

"I'm one of those people who goes by what the doctor says; if the doctor tells me to stand on my head, I'm going to stand on my head." 
Others desired a highly active role in decision-making, and the remainder fell somewhere in between these two extremes. Some women felt that the physician's approach to including them in decision-making was consistent with their preferred role, while others would have liked to be more involved, felt like they couldn't speak up, or didn't feel heard when they did.

"I brought it up to the surgeon, and he looked at me and he goes - 'X, come on. We've done this how many times? Let's just keep going with this right now. 'And he goes - 'I'll tell you when you need to start thinking about something different.",

Decisional Inputs: Medical information, from both inside and outside of the health care system, was a factor in decision-making for most women. Information from inside the health care system came from women's health care providers, their own knowledge as a health care provider, and friends and family members who did not provide direct care to the patient but were in a health field.

"I think, as a nurse, I had a clinical understanding and approached it with, 'Okay, I know why it needs to be done.",

Outside the health care system, women found information online and elicited information from friends, family members, and/or colleagues, some of whom had personal experience with AH/LCIS or breast cancer. Some women had a personal history of multiple breast biopsies, other health issues, health preferences, and/or a family history of breast cancer that influenced their decision-making. We also found that some women felt that they couldn't really "hear" the information given early in the process because of their emotional state.

"I don't think I heard anything he [doctor] was saying, but his mouth was moving and he was ... giving me alternatives ... just giving me options and all I kept thinking about was, 'Grrr-grrrgrrr... do I have cancer? ",

Risk-Reducing Medication: Women's thoughts on whether or not they should take risk-reducing medication varied. Of the 20 women interviewed, 7 were taking a risk-reducing medication, 3 did not discuss it during the interview, 8 had declined to take it, and 2 had started then stopped due to side effects. Some women felt that it made sense to them from a risk-benefit perspective.

"It didn't make sense to not take something that had such a potential to reduce that risk."

Others felt the potential risks outweighed the benefits for them, and some women felt that taking a medication with potential side effects was not warranted since they did not have breast cancer. Others hesitated to take the medication for other reasons.

"I did look it [diagnosis] up online but, I just feel that it wasn't cancer ... why take that drug, I don't need that drug in my system ... that's how I feel...."

Understanding Risk and Benefit: Understanding the risks and benefits of treatment options is a critical part of shared decision-making. Women generally understood that there was an increased risk for breast cancer associated with AH/LCIS, but few knew how high the estimated risk is.

"I think they did [tell me about my risk for developing breast cancer], but I truly don't remember ... okay, it's like zero percent or something, but that can always change."

\section{Making Sense of AH/LCIS}

Also identified in interviews were ways in which women attempted to make sense of their diagnosis. This major theme had three associated subthemes: a) emotional responses; b) impact on life; c) supportseeking; and d) living in a grey zone.

Emotional Responses: Women expressed a range of emotional responses to the diagnosis, emotions that sometimes evolved over the course of their diagnostic and postdiagnosis experiences. Fear, urgency to "do something," pragmatism, relief, feeling that a cancer diagnosis was inevitable, concerns about body image and sexuality, changes in self-concept, the power that cancer-related terminology can have (weight of words), and how women envisioned the cancer in their bodies dominated these comments.

"But it absolutely 100 percent walloped me emotionally. Just because I was so scared, so worried."

"I just imagined that the mass they were talking about was a little something lumpy. Looked like maybe jelly or even like plastic or something ... little air balls and that made me imagine this is why the cancer cells could hide because it's so 
lumpy you can't really see it around the regular smooth ... that kind of got crumbled up and that it gives cancer a place to hide."

Impact on Life: The AH/LCIS diagnosis had little impact on some women's lives, while for others it had significant meaning. Some found positive takeaways from the experience, such as "silver linings":

"So, you know, shitty things can happen, but there's a silver lining because you see the good in so many people. It was a really big wake-up call. So now I'm more focused on eating better and taking care of myself and getting to the gym. I just have a new outlook in life."

For other women, it had a persistent negative effect, such as the discomfort of living with uncertainty.

"It's like in the forefront on my mind always ... I'm still really worried. I worry about it a lot. It's ... there, in the back of my mind ... and I try very hard to let it just be there and to live with it, but it's not a pleasant thing to have sitting back there.

Support-Seeking: Some women discussed the importance of the emotional support they received or the problem with the lack thereof, while others preferred to handle their diagnosis themselves and did not seek support. Family members specifically were a source of emotional support for some, while others felt that family added an emotional burden. Some participants discussed the challenge of needing to provide support for their children while also needing to take care of themselves. Women also described the role of faith in coping with the diagnosis.

"It's funny because normally you would worry and all that, and I just said, 'You know what, it's in God's hands. I can't change it, you know? ',

Living in a Gray Zone: Some women talked about the difficulty they had explaining their condition to others because it was not a cancer diagnosis but is associated with an increased risk for developing cancer.

"Dr. $X$ and I were talking this spring; she thought there's really no place for somebody like me and other women ... that went through this ... because there's no Pink [ribbon] to celebrate it and there are no support groups. But you know what? It's still scary and it's still a big decision.

\section{Triangulation of Major Themes and Subthemes With Decision Theory}

Classical behavioral economics stipulates that people make rational decisions based on the highest overall benefit or utility (rational choice theory). ${ }^{25}$ However, clinical decision-making consistently deviates from rational choice theory, deviations explained by prospect theory, which takes into account emotional aspects of decision-making. ${ }^{26}$ The narratives women shared gave evidence for both intuitive and analytic models of decision-making, with emotions playing an important role in intuitive decision-making. Many women in the study demonstrated reliance on classic decisional heuristics such as availability (eg, memories of recent or vivid experiences), anchoring biases (eg, relying on the first piece of information offered), loss aversion (eg, tendency to avoid a bad outcome even if the "risk" of that outcome is low, such as side effects of risk-reducing medication), decisional regret (eg, a decision is assessed based on which decision pathway will feel "less bad" if the eventual outcome is undesirable), and affective heuristics (eg, focus on values most pertinent to the individual). ${ }^{26}$

The close relationship between the factors that women indicated influenced their decisions provides important information for tailoring approaches to informed shared decision-making regarding risk-reducing medications for $\mathrm{AH} / \mathrm{LCIS}$.

\section{DISCUSSION}

In this qualitative study of women's experiences with $\mathrm{AH}$ or LCIS, women shared stories of both positive and negative experiences with the health care system, factors that potentially influenced their decisionmaking related to diagnosis, and how they made sense of their experience. Each of the major themes we identified has the potential to inform how a decision aid might best serve women with the diagnosis of AH/LCIS and their health care providers. Perhaps not surprisingly, women's perspectives varied, highlighting the importance of the opportunity a decision aid based on shared decision-making principles offers.

More than 30 years after Page and colleagues described the pathological findings of $\mathrm{AH},{ }^{27}$ questions about individual risk and disease management remain. The impact of age at diagnosis and family history on the risk estimate is debated. ${ }^{11}$ Recommendations regarding 
the need for excisional biopsy, optimal imaging, and identification of women most likely to benefit from risk-reducing medication continue to evolve. ${ }^{11}$

Ensuring that women fully understand the concept of breast cancer risk over time is of paramount importance. For $\mathrm{AH}$, the cumulative incidence of breast cancer may be estimated to range from $18 \%$ to $40 \%$ based on stratification by multiple foci of atypia. ${ }^{4}$ Once there is an understanding of risk, then a discussion can begin regarding the reduction in risk conferred by medication and how this measures against the probability of medication-associated adverse effects. The experiences and perspectives of the women in the current study reinforce the importance of many of these recommendations.

Shared decision-making generally has three components: 1) introducing decisions to be made; 2) describing options, often integrating use of a decision support aid; and 3) helping patients explore their preferences based on their values and life context. ${ }^{28}$ There appeared to be some variation in the recommendations made to women participating in this study both within and across disciplines. We also found that while some women clearly understood that their risk for developing invasive breast cancer was substantially elevated, others seemed to have only a vague sense that their risk was higher than average. Many were not clear on the role of risk-reducing medication for breast cancer prevention. These findings suggest that a decision aid might prove useful for women facing a diagnosis of AH/LCIS and may help their health care providers elicit individualized value-based and life-context preferences.

Prior studies have shown that insufficient understanding about breast cancer risk contributed to women's decision to decline a risk-reducing medication. ${ }^{29-31}$ Holmberg et al conducted a narrative study of women's decisions regarding risk-reducing medication and found that epidemiological data alone is not sufficient for informed patient-centered decision-making about chemoprevention $^{32}$ and that whether AH/LCIS is framed as a disease or as a risk factor for disease makes a difference in how women perceive risk of the medication. This was consistent with the findings of Salant et $\mathrm{al}^{33}$ and Rondanina et al, who reported that women who felt that all their questions had been answered by their clinician were more likely to take a risk-reducing medication. ${ }^{34}$

The framework for decision-making in breast cancer prevention formulated by Ozanne et al relies largely on epidemiologic data, ${ }^{35}$ which is important, but this study suggests that such a framework might benefit from explicitly including exploration of theory-informed intuitive elements of decision-making, such as values and life context, along with analytic elements such as numerical risks and benefits of decisions.

\section{Limitations}

Although the study was not designed to recruit a representative sample, it is a strength that nearly $30 \%$ of participants identified with a racial or ethnic minority population. One limitation of the study is that because the registry from which women were recruited is a tissue registry, most study participants had had a surgical excision (vs only a percutaneous core needle biopsy). Women who have only had a stereotactic core biopsy may have a different perspective of risk. Women in the registry are from one geographic region, which could mean that their experiences reflect dominant local practice. However, a number of women reported receiving conflicting advice about management from health care providers, making it less likely that homogeneous local practice would have influenced findings. The women in the study had relatively high levels of educational attainment; women with lower educational attainment may have offered different perspectives.

We only included women's perspectives and recollections, and their health care providers may have had differing perspectives. It is somewhat unusual for women with AH/LCIS to have had a mastectomy, which also may have influenced some of our findings.

\section{CONCLUSIONS}

The narratives women shared in this study provide important insights into the current state of informed shared decision-making for patients diagnosed with atypical hyperplasia or lobular carcinoma in situ. Our findings suggest that a decision support aid that provides a framework for systematically incorporating both analytic and patient-specific contextual decisional inputs into decision-making, versus a primarily 
analytic-focused approach, could benefit women and health care providers in helping women make more fully informed decisions regarding use of riskreducing medication for breast atypia.

\section{Patient-Friendly Recap}

- Certain breast lesions, known as atypical hyperplasia or lobular carcinoma in situ, are benign in nature. However, women with these lesions are at greater risk to develop harmful breast cancer later in life.

-Woman diagnosed with benign breast atypia may be offered risk-reducing medication, but few choose to use it.

- The authors found that women base their decision whether or not to use medication on myriad factors beyond the statistical risk of developing cancer.

- Health care providers can benefit from discerning each patient's level of understanding and personal values when attempting to inform clinical decisions.

\section{Acknowledgments}

We would like to thank Dr. Anita Mulye for her role in interviewing patients in this study.

\section{Author Contributions}

Study design: all authors. Data acquisition or analysis: all authors. Manuscript drafting: Goff. Critical revision: Kleppel, Makari-Judson.

\section{Conflicts of Interest}

None.

\section{Funding Sources}

Financial support for this study was provided in part by a grant from the Rays of Hope Center for Breast Cancer Research (Springfield, MA). Dr. Goff is supported in part by a National Institutes of Health (NIH) Career Development Award (NICHD K23HD080870). Dr. Makari-Judson is supported in part by NIH cooperative agreement U01ES026140. The funding agreement ensured the authors' independence in designing the study, interpreting the data, writing, and publishing the report.

\section{References}

1. Simpson JF. Update on atypical epithelial hyperplasia and ductal carcinoma in situ. Pathology. 2009;41:36-9. CrossRef

2. Castells X, Domingo L, Corominas JM, et al. Breast cancer risk after diagnosis by screening mammography of nonproliferative or proliferative benign breast disease: a study from a population-based screening program. Breast Cancer Res Treat. 2015;149:237-44. CrossRef

3. Collins LC, Aroner SA, Connolly JL, Colditz GA, Schnitt SJ, Tamimi RM. Breast cancer risk by extent and type of atypical hyperplasia: an update from the Nurses' Health Studies. Cancer. 2016;122:515-20. CrossRef

4. Degnim AC, Dupont WD, Radisky DC, et al. Extent of atypical hyperplasia stratifies breast cancer risk in 2 independent cohorts of women. Cancer. 2016;122:2971-8. CrossRef

5. Hartmann LC, Radisky DC, Frost MH, et al. Understanding the premalignant potential of atypical hyperplasia through its natural history: a longitudinal cohort study. Cancer Prev Res (Phila). 2014;7:211-7. CrossRef

6. Dyrstad SW, Yan Y, Fowler AM, Colditz GA. Breast cancer risk associated with benign breast disease: systematic review and meta-analysis. Breast Cancer Res Treat. 2015;149:569-75. CrossRef

7. Oppong BA, King TA. Recommendations for women with lobular carcinoma in situ (LCIS). Oncology (Williston Park). 2011;25:1051-6, 1058.

8. Chen WY, Rosner B, Hankinson SE, Colditz GA, Willett WC. Moderate alcohol consumption during adult life, drinking patterns, and breast cancer risk. JAMA. 2011;306:1884-90. CrossRef

9. Gaudet MM, Carter BD, Patel AV, Teras LR, Jacobs EJ, Gapstur SM. Waist circumference, body mass index, and postmenopausal breast cancer incidence in the Cancer Prevention Study-II Nutrition Cohort. Cancer Causes Control. 2014;25:737-45. CrossRef

10. Saslow D, Boetes C, Burke W, et al. American Cancer Society guidelines for breast screening with MRI as an adjunct to mammography. CA Cancer J Clin. 2007;57:75-89. CrossRef

11. Hartmann LC, Degnim AC, Santen RJ, Dupont WD, Ghosh K. Atypical hyperplasia of the breast - risk assessment and management options. N Engl J Med. 2015;372:78-89. CrossRef

12. Fisher B, Costantino JP, Wickerham DL, et al. Tamoxifen for the prevention of breast cancer: current status of the National Surgical Adjuvant Breast and Bowel Project P-1 study. J Natl Cancer Inst. 2005;97:1652-62. CrossRef

13. Cuzick J, Sestak I, Thorat MA. Impact of preventive therapy on the risk of breast cancer among women with benign breast disease. Breast. 2015;24 Suppl 2:S51-5. CrossRef

14. Mocellin S, Pilati P, Briarava M, Nitti D. Breast cancer chemoprevention: a network meta-analysis of randomized controlled trials. J Natl Cancer Inst. 2016;108(2). CrossRef

15. Freedman AN, Graubard BI, Rao SR, McCaskill-Stevens W, Ballard-Barbash R, Gail MH. Estimates of the number of US women who could benefit from tamoxifen for breast cancer chemoprevention. J Natl Cancer Inst. 2003;95:526-32.

16. Waters EA, McNeel TS, Stevens WM, Freedman AN. Use of tamoxifen and raloxifene for breast cancer chemoprevention in 2010. Breast Cancer Res Treat. 2012;134:875-80. CrossRef

17. O'Connor AM, Llewellyn-Thomas HA, Flood AB. Modifying unwarranted variations in health care: shared decision making using patient decision aids. Health Aff (Millwood). 2004;Suppl Variation:VAR63-72.

18. Greenhalgh T, Russell J, Swinglehurst D. Narrative methods in quality improvement research. Qual Saf Health Care. 2005;14:443-9. CrossRef 
19. Glaser BG, Strauss AL. The Discovery of Grounded Theory: Strategies for Qualitative Research. Chicago: Aldine, 1967.

20. Goff SL, Mazor KM, Gagne SJ, Corey KC, Blake DR. Vaccine counseling: a content analysis of patient-physician discussions regarding human papilloma virus vaccine. Vaccine. 2011;29:7343-9. CrossRef

21. Goff SL, Kleppel R, Lindenauer PK, Rothberg MB. Hospital workers' perceptions of waste: a qualitative study involving photo-elicitation. BMJ Qual Saf. 2013;22:826-35. CrossRef

22. Goff SL, Mazor KM, Ting HH, Kleppel R, Rothberg MB. How cardiologists present the benefits of percutaneous coronary interventions to patients with stable angina: a qualitative analysis. JAMA Intern Med. 2014;174:1614-21. CrossRef

23. Goff SL, Eneanya ND, Feinberg R, et al. Advance care planning: a qualitative study of dialysis patients and families. Clin J Am Soc Nephrol. 2015;10:390-400. CrossRef

24. Corbin J, Strauss A. Basics of Qualitative Research: Techniques and Procedures for Developing Grounded Theory, Third Edition. Thousand Oaks, CA: Sage Publications, 2008.

25. Elwyn G, Stiel M, Durand MA, Boivin J. The design of patient decision support interventions: addressing the theorypractice gap. J Eval Clin Pract. 2011;17:565-74. CrossRef

26. Haward MF, Janvier A. An introduction to behavioural decision-making theories for paediatricians. Acta Paediatr. 2015;104:340-5. CrossRef

27. Page DL, Dupont WD, Rogers LW, Rados MS. Atypical hyperplastic lesions of the female breast. A long-term followup study. Cancer. 1985;55:2698-708. CrossRef

28. Elwyn G, Frosch D, Thomson R, et al. Shared decision making: a model for clinical practice. $J$ Gen Intern Med. 2012;27:1361-7. CrossRef
29. Bambhroliya A, Chavez-MacGregor M, Brewster AM. Barriers to the use of breast cancer risk reduction therapies. J Natl Compr Canc Netw. 2015;13:927-35. CrossRef

30. Heisey R, Pimlott N, Clemons M, Cummings S, Drummond N. Women's views on chemoprevention of breast cancer: qualitative study. Can Fam Physician. 2006;52:624-5.

31. Smith SG, Sestak I, Forster A, et al. Factors affecting uptake and adherence to breast cancer chemoprevention: a systematic review and meta-analysis. Ann Oncol. 2016;27:575-90. CrossRef

32. Holmberg C, Daly M, McCaskill-Stevens W. Risk scores and decision making: the anatomy of a decision to reduce breast cancer risk. J Nurs Healthc Chronic Illn. 2010;2:271-80. CrossRef

33. Salant T, Ganschow PS, Olopade OI, Lauderdale DS. "Why take it if you don't have anything?" Breast cancer risk perceptions and prevention choices at a public hospital. J Gen Intern Med. 2006;21:779-85. CrossRef

34. Rondanina G, Puntoni M, Severi G, et al. Psychological and clinical factors implicated in decision making about a trial of low-dose tamoxifen in hormone replacement therapy users. J Clin Oncol. 2008;26:1537-43. CrossRef

35. Ozanne EM, Klemp JR, Esserman LJ. Breast cancer risk assessment and prevention: a framework for shared decisionmaking consultations. Breast J. 2006;12:103-13. CrossRef

(C) 2018 Aurora Health Care, Inc.

\section{Appendix 1. Atypical Hyperplasia (AH/LCIS) of the Breast: Interview Guide}

1. Please tell me/us a little bit about yourself. [Prompt: Anything important to know about you, maybe about family, hobbies and interests, work if that applies?]

2. People have different and varying perspectives or understanding of $A H / L C I S$, so l'd like to ask you to share your understanding about your diagnosis of (AH/LCIS). [Prompt: What is known about risks for developing it, how it relates to breast cancer risk?]

3. Now could you tell me about what you remember about finding out about your diagnosis? [Prompt: Who told you? How did you feel when you first found out? How do you feel about the diagnosis now? Who did you tell about the diagnosis?]

4. Now l'd like to ask you to take me through the steps you took after finding out about your diagnosis. [Prompt: chemoprevention, screening and follow-up, second opinion, own research, decisions made, decision inputs, follow-up plans, resources, social network, physicians, nurses, books, internet]

- What sources of information did you find most helpful, if any?

- Was there anything you wanted to know but couldn't find information about?

- If another woman asked your advice on what to do after receiving the diagnosis, what might you tell her?

5. Can you tell me a little about how this diagnosis impacted you initially, if at all? How has that changed, if at all, since you were diagnosed? [Prompt: Emotional aspects, family life, evolution of perceptions]

6. Knowing what you know now, can you tell me about anything you think you might have done differently? [Prompts: Not undergone certain tests, procedures, not sought other opinions, obtained second opinions]

7. Is there anything else you think is important that you would like us to know? 